\title{
INVESTIGACIONES
}

\section{Un estudio de caso sobre la idealización y representación de la familia en los centros educativos}

\author{
A case study on the idealization and representation of the family in schools
}

\author{
José Antonio Rodríguez-Mena ${ }^{a}$, Emilia Moreno Sánchez, \\ Inmaculada Montérdez Santos ${ }^{c}$ \\ ${ }^{a}$ Universidad de Huelva. \\ Correo electrónico: jarodriguezmena@gmail.com \\ ${ }^{\mathrm{b}}$ Universidad de Huelva. \\ Correo electrónico: emilia@uhu.es. \\ ${ }^{\mathrm{c}}$ Colegio Profesional de Trabajo Social de Sevilla Consejo Andaluz \\ de Colegios Profesionales de Trabajo Social. \\ Correo electrónico: imonterdez@gmail.com.
}

\begin{abstract}
RESUMEN
Una característica de nuestra sociedad actual, es la diversidad de modelos familiares que la configuran. Esta situación ha supuesto la ruptura de la hegemonía del modelo tradicional de familia. La escuela ha de entender estos cambios e incluir el universo familiar en su trabajo educativo. Desde una perspectiva cualitativa, basada en el estudio de caso, en este artículo presentamos una investigación en la que se analiza las imágenes vinculadas con la familia en los libros de texto, carteles, murales; el lenguaje utilizado en las comunicaciones y notas del centro; y el concepto de familia entre los miembros de la comunidad educativa. Los resultados indican que un sector de la comunidad educativa comparte un concepto de familia basado en la heteronormatividad y la consanguinidad, y que los documentos y materiales analizados muestran una imagen sesgada de la familia.
\end{abstract}

Palabras clave: Escuela primaria, diversidad familiar, educación inclusiva, preconceptos.

\begin{abstract}
The diversity of family models is one of the factors shaping our current society. This situation has led to the rupture of the traditional model of family hegemony. These changes have to be understood by schools, and this new family realm has to be included in their educational work. In this article, we present a study which, from a qualitative perspective based on a case study, analyzes linked images to family in textbooks, on posters and murals; in the language used in communications and notes addressed to families; and finally, in the concepts of family that exist among the members of the educational community. The results indicate that one sector of the educational community shares a family concept based on heteronormativity and consanguinity, and that the materials and documents analyzed show a biased picture of the family.
\end{abstract}

Keywords: Primary school, family diversity, inclusive education, preconceptions. 


\section{INTRODUCCIÓN}

En nuestro país, el sistema familiar ha experimentado en los últimos años una transformación estructural y funcional de los miembros que la integran. La característica más notable de este cambio es la diversificación de los modelos que forman parte de este sistema. Este fenómeno ha sido constatado por el Instituto Nacional de Estadística a través de sus principales instrumentos demográficos (INE 2017). En la ruptura de la hegemonía del modelo tradicional de familia, nuclear y heteroparental, han intervenido una serie de factores entre los que se encuentran: la proliferación de familias de uniones no matrimoniales; la ausencia de uno de los progenitores, como es el caso de las familias monoparentales; la adopción y la reproducción asistida; la reducción del número de hijos/as; la disolución del núcleo familiar por separación o divorcio; y la reconstitución de nuevas familias con hijos/ as de matrimonios anteriores (Rodrigo y Palacios 1998). Además, la regulación en el año 2005 del matrimonio entre personas del mismo sexo, con plenitud e igualdad de derechos y obligaciones que el resto de matrimonios, ha incrementado notablemente el número de familias homoparentales y homomarentales.

Esta diversidad familiar se ha visto apelada por las actitudes, prácticas, expectativas y creencias de una sociedad que ha tenido como referente el modelo familiar nuclear, la relación de consanguinidad entre los miembros de la unidad familiar y la heteronormatividad.

Las organizaciones escolares tienen la responsabilidad de reconocer y aceptar esta diversidad, incluirla en sus principios educativos como un valor para el desarrollo integral de sus alumnos y alumnas, y articular medidas que acerquen sus prácticas curriculares a las diferentes identidades familiares que forman parte de ellas. Si no existe este compromiso "no podemos hablar con propiedad de políticas de equidad, de modelos educativos justos, de justicia curricular" (Torres 2015). Como apunta López, las escuelas han tratado la diversidad familiar con cierta indiferencia y han manifestado ciertos prejuicios en relación a determinados modelos familiares (López 2006), como se muestran en las conclusiones de algunos estudios (Ramírez, Moliner y Vicente 2007; Morgado, Jiménez-Lagares y González 2009; Ros 2012). La familia se presenta de cómo una realidad uniforme en los libros de textos, cuentos, carteles, formularios, comunicaciones dirigidas a las familias y los elementos simbólicos del centro. La homogeneidad con la que se muestra la familia interfiere en el reconocimiento de la diversidad familiar y supone una situación de discriminación para los menores que no pertenecen a las llamadas familias tradicionales. Con este enfoque, se han realizado algunos estudios que han analizado la representación de la familia en los materiales y contenidos escolares, y que veremos a continuación.

Jennings y Macgillivray, analizaron el contenido de los manuales educativos sobre diversidad dirigidos al profesorado. En el proceso de análisis se identificaron las entradas en los índices y tablas que tenían relación con los temas LGBT y posteriormente fueron explorados página por página, para localizar el contenido que no hubiese sido citado en los índices y tablas. Una vez que se identificaron las ilustraciones y secciones de texto, fueron codificadas y agrupadas por categorías temáticas. En una de las categorías definidas se agruparon los contenidos relacionados con la familia LGBT. Según los resultados obtenidos para esta categoría en algunos de los manuales se mencionaba a las familias LGBT, pero no se incluían fotografías de familias con hijos/as. Solo en uno de los materiales analizados se hallaron referencias a las barreras sociales a las que se enfrenta la familia. Un aspecto que resulta llamativo, es que estos temas se incluyeron dentro o junto a apartados en los que se 
trataban temas como el abuso de drogas, el SIDA, la violencia, la depresión y el suicidio (Jennings y Macgillivray 2011).

Los docentes deben reflexionar detenidamente sobre los contenidos de los materiales que utilizan en el aula. Los libros tienen el poder de llegar al corazón y a la mente del lector, sea cual sea su edad (Rowell 2007). Muchas de las colecciones dedicadas a los/ as menores incluyen contenidos relacionados con sus propias características, amigos/as y familias. Sin embargo, son escasas las editoriales que integran en sus materiales a las familias homoparentales. La inclusión de las familias de gais y lesbianas en los contenidos e ilustraciones de los materiales escolares mejoraría el currículo y contribuiría al desarrollo del alumnado. Las familias compuestas por padres del mismo sexo, así como sus familiares y amigos, se sentirán más cerca e identificados con los materiales utilizados en la escuela de su hijo o de su hija, y los niños y niñas de otras estructuras familiares podrán comprender y apreciar la riqueza de la diversidad, lo que contribuirá a prevenir y poner fin a la estigmatización y el acoso que sufren algunos y algunas menores. Finalmente, Rowell afirma que, si hoy día la mayoría de las escuelas cuenta con una gran variedad de libros que tratan la diversidad cultural, el siguiente paso debe ser que estos materiales también reflejen la diversidad familiar, puesto que los chicos y chicas se sentirán más identificados y, podrán aprender de familias diferentes a las suyas (Rowell 2007).

En las conclusiones del trabajo realizado por Agustín, se plantea la necesidad de incluir en los materiales y contenidos escolares, los modelos familiares no convencionales: Familias LGBT, madres y padres solteros, familias con hijos/as de matrimonios anteriores (Agustín 2014). Igualmente, los resultados del estudio de Ros, indican que en los libros de textos y de lectura analizados, los modelos familiares más ausentes fueron las familias de acogida, adoptiva, homoparental y divorciadas. Tampoco se localizaron en estos textos, ilustraciones o contenidos referentes a personas homosexuales. Se revisaron las comunicaciones del centro enviadas a las familias y se comprobó que se utiliza habitualmente fórmulas heteronormativas, como "padre/madre", que no representa la realidad de la familia homoparental (Ros 2012). Esta necesidad, es demandada igualmente por los padres gais y madres lesbianas en el estudio realizado por Ray y Gregory, en el que se muestra la ausencia de publicaciones y materiales que contemplen su modelo familiar (Ray y Gregory 2001). Igualmente, en la investigación realizada por Ceballos, las familias homoparentales y homomarentales participantes, pusieron de manifiesto la invisibilidad de su modelo familiar y el de otras tipologías familiares no convencionales en los libros educativos. Otra de las conclusiones que se llegan en este mismo estudio, es la referencia directa de la figura materna, por parte del profesorado y en los materiales didácticos, cuando se abordan el tema de la familia (Ceballos 2009).

Teniendo en cuenta las cuestiones anteriores, hemos realizado este estudio con el objetivo de analizar: las imágenes incluidas en los libros de texto, de conocimiento del medio, vinculadas con la familia; los carteles, murales, comunicaciones y notas del centro; y el concepto de familia entre la comunidad educativa.

\section{METODOLOGÍA}

Con un diseño metodológico cualitativo y naturalista, se ha estudiado el caso de un Colegio Público de Educación Infantil y Primaria situado en Huelva (Andalucía, España). Con esta 
estrategia metodológica se ha pretendido superar el reduccionismo positivista y producir una información más significativa, relevante y exhaustiva, sobre situaciones y contextos particulares (Johnson \& Christensen 2004). Para seleccionar este centro se siguieron los criterios de relevancia y accesibilidad descritos tradicionalmente en los estudios de casos (Stake 1998; Rodríguez, Gil y García 1996; Simons 2011).

En esta investigación han participado doce docentes, doce familias y un miembro del personal no docente del centro. Para selección de la muestra se tuvo en cuenta la participación de docentes de todos los ciclos educativos, la vinculación permanente con el centro, el número de años en ejercicio y la representación de hombres y mujeres; en el caso de las familias, se trató que en la muestra estuvieran representados el mayor número de modelos familiares; y finalmente, entre el personal no docente contamos con la participación de la persona con mayor vinculación laboral con el centro.

Para explorar el concepto de familia, se realizaron un total de 28 entrevistas semiestructuradas. Además, se ha utilizado el análisis de documentos, como una técnica no interactiva que ha permitido explorar y analizar los libros de textos, los carteles, murales, comunicaciones y notas del centro. Nos centramos en los libros de textos del área de conocimiento de medio, por su mayor vinculación con los contenidos relacionados con la familia. En el análisis se describen los modelos familiares representados en las imágenes que contienen este material didáctico, y su relación con las actividades, contenidos y objetivos propuestos.

Para ordenar y sistematizar la información obtenida en las técnicas descritas anteriormente se elaboró un sistema de categorías mediante procedimientos tanto deductivos como inductivos; es decir, tras la revisión de la literatura, elaboramos las primeras categorías (deducción), y posteriormente, el sistema de categorías inicial se fue reconstruyendo en función de las nuevas categorías y relaciones que surgieron del análisis de la información obtenida (inducción).

\section{RESULTADOS}

\subsection{CONCEPTO DE FAMILIA ENTRE LA COMUNIDAD EDUCATIVA}

En esta investigación planteamos al profesorado, a las familias y al personal no docente del centro estudiado que nos aportaran una definición propia de la familia. Los resultados obtenidos contienen una serie de conceptos comunes y diferenciadores. Para ofrecer una idea general de los conceptos referenciados, aportamos la siguiente nube (Figura 1), donde se representan según el tamaño de cada palabra su repetición en el texto.

La idea que aparece con mayor frecuencia, es la importancia que tiene la familia en la vida de las personas entrevistadas; valorándose como un pilar fundamental en la vida de las personas. La familia se concibe como una importante fuente de protección, cuidado, apoyo, afectividad y educación para los menores. Además, se señala el significativo papel que juega en el equilibrio psicológico de sus miembros y, la ayuda que ofrece para superar los problemas.

Respecto a la estructura familiar, se hace referencia a modelos familiares muy diferentes. La posición más conservadora, la encontramos en la definición aportada por dos docentes (P3; P11), en las que se expresa una idea familiar exclusivamente heteroparental. 


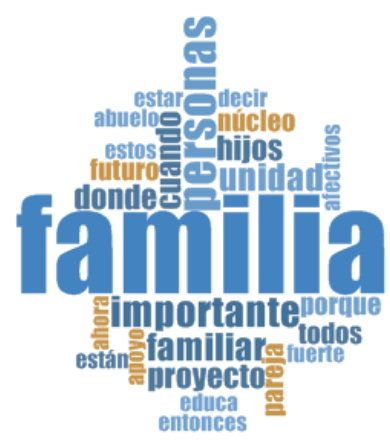

Figura 1. Repetición de las palabras empleadas en la definición de la familia.

Además, una de estas profesoras (P11), realza los valores del modelo familiar tradicional de la dictadura.

P3: Es el núcleo principal donde el niño se educa, pienso que mientras más extensa sea la familia es mucho mejor porque el niño tiene más modelos. El núcleo familiar formado solo por un padre y una madre es un problema cuando los dos trabajan, que es lo habitual hoy en día.

P11: Yo vengo de una generación donde la familia es muy importante, la dictadura y la unidad familiar estaban muy unidas. Yo estoy educada en esa cultura y entonces esos valores familiares para mí siguen siendo muy importantes.

Otras de las características que se destaca (P7) es la consanguinidad de los miembros de la unidad familiar.

P7: Es todo, es tus raíces, de donde tú vienes, eres un poquito de cada miembro de tu familia y esto se lo intentó transmitir a mis alumnos.

Sin embargo, encontramos a otro grupo de sujetos (P10; P14; P16; F3) que en sus descripciones no reflejan la consanguinidad, el parentesco o el número de miembros. Para estas personas, la familia es un proyecto común de vida (P14), formado por una serie de personas que permanecen unidas por unos lazos afectivos (P10; P16), y cuya finalidad es el crecimiento y el desarrollo de sus miembros (P16). Desde esta perspectiva, se acentúa el papel de la convivencia familiar por encima de la consanguinidad (F3).

Según el testimonio de dos madres con un modelo familiar homoparental (FH1; FH3), la posición tradicional que algunas personas mantienen sobre el concepto de familia, genera cierta conflictividad a sus hijos/as; es decir, a los/as menores que viven estos ideales les resulta muy complicado encajar en su esquema de referencia a otros modelos familiares. En este sentido, son habituales las escenas en las que estos/as menores interpelan a sus hijos/as ante su incredulidad. Como ejemplo, incluimos la siguiente anécdota que nos cuenta una madre (FH1) sobre la conversación que mantiene su hija con una conocida. 
EFH1: Hace unos días me harté de reír, porque le dice una niña a mi hija "¿tú no tienes padre?" y ella le responde: no, yo tengo dos madres; y la niña le dice "eso es imposible". Mi hija vuelve a responderle "no es imposible, hay niños que tienen dos mamas, hay niños que tienen dos papas, hay niños que tienen un papa solo o una mama sola, y niños que no tienen ni papa ni mamá". Entonces la chica le responde, dos mamás puede ser, pero dos papás es imposible (reímos). Y me mira a mí como diciendo ¿a que sí?, y yo le digo pues no (reímos).

\subsection{CARTELES, MURALES, COMUNICACIONES Y NOTAS DEL CENTRO}

Las familias homoparentales (FH1; FH3) afirman que en las comunicaciones que reciben y las solicitudes que deben cumplimentar, no se utiliza un leguaje inclusivo. Las fórmulas empleadas habitualmente son: queridos padres, queridos padres y madres. Esta situación es habitual y para dejar constancia de su desacuerdo suelen tachar el apartado destinado a la firma del padre, para hacer constar su realidad familiar.

Estos datos fueron corroborados por el equipo de investigación mediante el análisis de los documentos del centro. Por ejemplo, en el Contrato de Compromiso de Convivencia, un documento dirigido a las familias, comprobamos que se utiliza un leguaje dirigido únicamente a las familias heteroparentales; es decir, se incluye dos apartados para reseñar los datos del padre y de la madre. Además, en el pie de firma de estos documentos, se hace un uso discriminatorio del leguaje utilizándose la forma genérica "Los padres".

Una de las actividades que tradicionalmente se celebran en los centros educativos, es el día del padre y de la madre. Este ritual, con un origen comercial, realza el modelo de familia tradicional y heteroparental. Durante la celebración de estas efemérides conseguimos recopilar algunos vestigios que ponen de relieve la situación en la que se enfrentan los menores que no cumplen con las expectativas del modelo familiar heteroparental. Por ejemplo, en el aula matinal, nos encontramos con un gran mural realizado con corbatas de papel en el que figuraba escrito "felicidades papá", y entre el material que se preparan para este día, localizamos en la sala de profesores algunas fichas para colorear (Figura 2) en la que se representan a la familia nuclear.

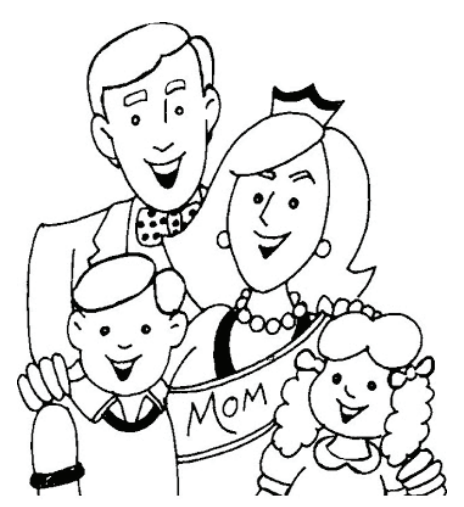

Figura 2. Ficha para colorear I. 


\subsection{LIBROS DE TEXTO}

Como hemos comentado anteriormente, decidimos centrar el análisis de los libros de textos del área de conocimiento del medio por ser la materia con mayor vinculación con la familia. Las editoriales utilizadas en el centro para el desarrollo de esta asignatura son Edelvives (Pixépolis), en el caso de la etapa de educación primaria, y Algaida (Pompas de jabón), en la etapa de educación infantil. Para llevar a cabo el análisis revisamos las propuestas didácticas para el docente (Campuzano 2014; Segura 2012; Mancheño 2012; Trébol 2012; Escamilla 2012), en las que se incluyen, además del material del alumnado, las sugerencias y objetivos de las actividades propuestas. El procedimiento que seguimos consistió en seleccionar las imágenes vinculadas a la familia; a continuación, se revisó los modelos familiares representados en ellas; y finalmente, se exploró su relación con el contenido que les acompañan. Antes de empezar con la exposición de los resultados, debemos decir que se seleccionó un total de 27 imágenes vinculadas con el ámbito familiar (Tabla 1). Habitualmente, estas imágenes se incluyen para ilustrar las actividades y contenidos relacionados con la familia. El mayor número de ellas, se localizaron en el libro de texto de primer curso de educación primaria $\left(\mathrm{f}_{\mathrm{i}}=12\right)$ (Segura, 2012), y en el de educación infantil de tres años $\left(\mathrm{f}_{\mathrm{i}}=5\right)$ (Campuzano 2014).

Tabla 1. Frecuencia de imágenes relacionadas con la familia según el curso escolar

\begin{tabular}{|l|c|l|c|l|c|}
\hline Curso escolar & $f_{i}$ & Curso escolar & $f_{i}$ & Curso escolar & $f_{i}$ \\
\hline E. Infantil 3 años & 5 & $1^{\circ}$ E. Primaria & 12 & $4^{\circ}$ E. Primaria & 3 \\
\hline E. Infantil 4 años & 3 & $2^{\circ}$ E. Primaria & 2 & $5^{\circ}$ E. Primaria & 0 \\
\hline E. Infantil 5 años & 0 & $3^{\circ}$ E. Primaria & 2 & $6^{\circ}$ E. Primaria & 0 \\
\hline
\end{tabular}

Fuente: Elaboración propia a partir de los datos recabados de las propuestas didácticas de los libros de textos de conocimiento del medio (Campuzano 2014; Segura 2012; Mancheño 2012; Trébol 2012; Escamilla 2012).

En general, los resultados obtenidos muestran que en los libros de textos analizados se representa a la familia de manera homogénea y según el canon del modelo familiar nuclear y su variante extensa. En un segundo plano, aparecen algunas ilustraciones en las que se presentan a la figura materna o paterna por separado, pero no podemos llegar a la conclusión de que se traten de familias monoparentales, puesto que el contenido que acompaña a estas ilustraciones no hace referencia a este modelo familiar. Las estructuras familiares menos convencionales, como la homoparental, están ausentes en todos los textos analizados.

La familia aparece ligada a temas como los roles y tareas domésticas, los miembros de la familia, las estancias del hogar, la salud y el cuidado del medio ambiente. También localizamos algunas imágenes, en una menor proporción, relacionadas con la utilización de las máquinas y herramientas, la empatía y la educación vial.

Un aspecto positivo que contienen las ilustraciones vinculadas a los roles y tareas del hogar, y la salud, es el reparto equilibrado de estas responsabilidades, sin hacer distinción 
en función del género. Los objetivos de las actividades propuestas consisten en identificar las tareas, valorar la importancia de la cooperación, fomentar la participación y desarrollar hábitos de conductas dentro de la convivencia familiar. Sin embargo, a pesar de los avances en los aspectos coeducativos, como vemos en la letra de la siguiente canción (Segura 2012: 110), la familia nuclear y extensa acapara el protagonismo en los materiales analizados.

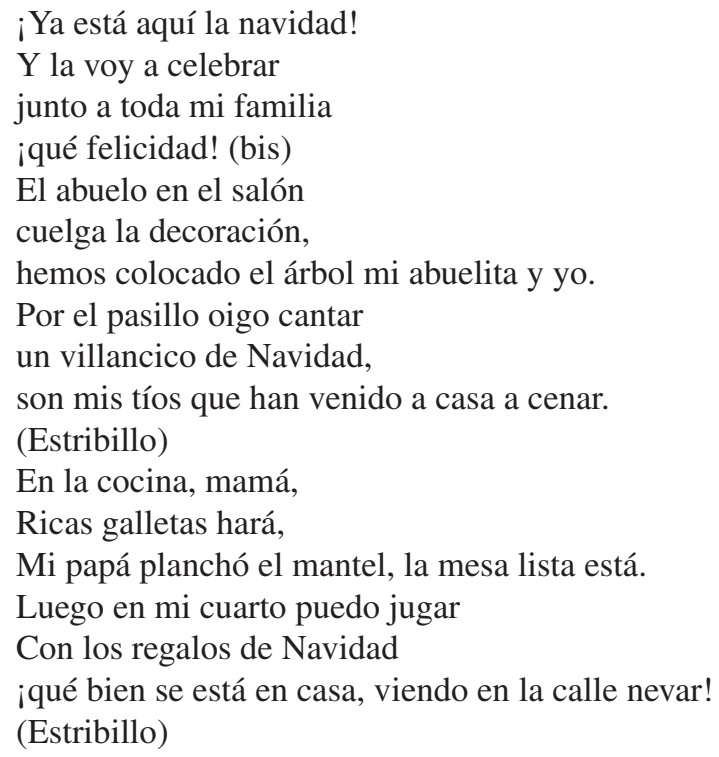

Un recurso empleado por la editorial Edelvives (Pixépolis), es la presentación de una familia de tipo nuclear (la familia de Bruno) como hilo conductor de las diferentes unidades didácticas. Para identificar los miembros de la familia y sus generaciones, se suelen incluir ilustraciones de árboles genealógicos. Estas imágenes ponen de manifiesto la relación sanguínea de sus miembros y la heteroparentalidad.

En el proyecto Pompas de Jabón de Algaida (Campuzano 2014), se presentan los contenidos de forma globalizada y entorno a los centros de interés "la casa y la familia". En la misma línea que la editorial Edelvives, el modelo de familia nuclear es el protagonista en las ilustraciones, murales, fichas y fotografías que se incluyen. Sobre estos materiales se plantean diferentes actividades relacionadas con la identificación de los miembros de la familia, las estancias del hogar, los roles y tareas, y la igualdad de género. Las indicaciones de las propuestas didácticas y, las actividades que se proponen, hacen referencia explícita a un único modelo familiar, el nuclear.

Por último, debemos destacar que los materiales analizados presentan un diseño cerrado; es decir, no se plantean actividades abiertas que permitan su adaptación a las particularidades familiares del alumnado. 


\section{DISCUSIÓN Y CONCLUSIONES}

El análisis del concepto de familia entre los miembros de la comunidad educativa, nos ha permitido obtener una serie de características compartidas y diferenciadoras que manifiestan la controversia de este concepto. Los elementos comunes destacan el valor de la familia como fuente de protección, cuidado, apoyo, afectividad y educación. También se alude al importante papel que juega en el equilibrio psicológico del menor y la ayuda a superar los problemas. A pesar de esta visión compartida, en las definiciones aportadas por un sector de la comunidad educativa, destacan algunas características como la heteroparentalidad, la consanguinidad y la nuclearidad. En cambio, en otras definiciones se pone un mayor énfasis en el papel de la convivencia de sus miembros, sin establecer límites por la consanguinidad o el parentesco. La apertura que caracteriza a este último grupo de definiciones, facilita la inclusión y el respeto a las diferencias familiares. Sin embargo, los conceptos basados exclusivamente en la heteroparentalidad y la nuclearidad, pueden generar algunas limitaciones y conflictos en los menores que desarrollan esta percepción de la familia.

En el centro escolar que se ha estudiado, se reproduce una imagen uniforme y estandarizada de la familia. Esta homogeneidad puede verse reflejada en las comunicaciones dirigidas a las familias, los carteles, las solicitudes, los folletos y símbolos. Los centros educativos deben revisar las comunicaciones y formularios dirigidos a las familias, eliminando las propuestas heteronormativas tradicionales y empleando en su lugar un leguaje inclusivo. Además, habría que revisar los materiales, carteles, elementos decorativos, etc., con el propósito de representar el universo familiar que convive en el centro.

Los resultados de nuestro estudio indican que los modelos familiares no convencionales están ausentes en los libros de textos analizados. Como subraya Torres "los libros de texto que circulan en las instituciones escolares del Estado español, las voces y representaciones de los otros son inexistentes o, en el mejor de los casos, una anécdota" (Torres 2008). La imagen de la familia que se representa se reduce al modelo nuclear y su variante extensa. En algunas ilustraciones aparece solamente la figura materna o paterna, pero no podemos llegar a la conclusión de que se traten de familias monoparentales, puesto que el contenido que se ilustra no hace referencia a este modelo familiar. Las investigaciones realizadas por Agustín y Ros coinciden con estos resultados, y muestran la necesidad de incluir en los materiales escolares la diversidad de formas familiares que existen en nuestra sociedad (Agustín 2014; Ros 2012).

El profesorado debe reflexionar detenidamente sobre el contenido de los materiales que se utilizan en el aula (Jessop y Williams 2009). Las editoriales escolares incluyen elementos relacionados con las características del alumnado, amigos/as y familias, pero las familias homoparentales están ausentes (Rowell 2007). La escuela no es una institución permeable a las actitudes, prácticas, expectativas y creencias de una sociedad basada en la heteronormatividad. En los materiales escolares se reproduce mediante el denominado currículum oculto (Torres 1991) el modelo familiar hegemónico, actualmente representado por la familia nuclear y heteroparental. Por tanto, los centros educativos deben prestar una especial atención sobre los contenidos, las imágenes y el lenguaje empleado en los recursos didácticos. Es necesario revisar los materiales escolares, "aprender a juzgarlos críticamente, a valorarlos, tratar de contrastarlos con otros y, por supuesto, a hacernos cargo de las valoraciones que hacemos y ser consecuentes con ellas" (Torres 2010). Hoy en día la mayoría de las escuelas cuentan con una gran variedad de recursos que tratan la 
diversidad cultural, el siguiente paso, como afirma Rowell, debe ser que estos materiales también reflejen la diversidad familiar (Rowell (2007).

En el proyecto educativo Pixépolis, de la editorial Edelvives, la familia aparece ligada a temas como los roles y tareas domésticas, los miembros de la familia, las estancias del hogar, la salud y el cuidado del medio ambiente. Se presenta una imagen de la familia vinculada exclusivamente al modelo nuclear y heteroparental. Un ejemplo de la hegemonía con la que se incluye este tipo de familia, es la utilización recurrente de "la familia de Bruno" (familia nuclear) como hilo conductor de las diferentes unidades didácticas. Debemos reconocer que las ilustraciones vinculadas con la salud y los roles y tareas del hogar, muestran un reparto equilibrado de estas responsabilidades, sin hacer distinciones en función del sexo. Sin embargo, algunas propuestas didácticas como la elaboración de árboles genealógicos, vincula la familia con la relación sanguínea de sus miembros y la heteroparentalidad.

Un aspecto que comparten los libros de textos analizados es su diseño cerrado, y esto impide al profesorado, como plantean Travé, Pozuelos y Cañal, la adaptación al medio próximo del alumnado. Sería necesario disponer de materiales que contengan propuestas abiertas que permitan su adaptación a las singularidades familiares del alumnado (Travé, Pozuelos y Cañal 2013).

En definitiva, como plantea Rowell la incorporación del modelo familiar homoparental en los contenidos e ilustraciones de los materiales escolares, mejoraría el currículo y contribuiría al desarrollo del alumnado. Las familias compuestas por parejas del mismo sexo, así como sus familiares y amigos/as, se sentirán más cerca e identificados con los materiales utilizados en la escuela de su hijo/a, y los niños y niñas de otras estructuras familiares podrán comprender y apreciar la riqueza de la diversidad, lo que contribuirá a prevenir y poner fin a la estigmatización y el acoso que sufren algunos/as menores. En este reto deben comprometerse la administración educativa, los profesionales de la educación y las editoriales escolares (Rowell 2007). Se trata de una cuestión de justicia curricular (Torres 2011).

Construir un sistema educativo justo y respetuoso con la diversidad, comprometido con proyectos curriculares antidiscriminación obliga, entre otras medidas, a prestar mucha atención a las políticas de recursos didácticos, de materiales curriculares, para que no funcione cual Caballos de Troya, cuyos contenidos ni docentes, ni estudiantes, ni sus familias aceptaría si fuesen conscientes de las manipulaciones, errores y sesgos que esconden en su interior (Torres 2011).

\section{REFERENCIAS BIBLIOGRÁFICAS}

Agustín, S. (2014). Necesidades infantiles y adolescentes en familias homoparentales. Un análisis desde la perspectiva de los padres y madres (Tesis Doctoral). Universidad Autónoma de Madrid, Madrid.

Campuzano, M. D. (2014). Proyecto Pompas de Jabón. Sevilla: Algaida.

Ceballos, M. (2009). La educación formal de los hijos e hijas de familias homoparentales: Familia y escuela a contracorriente. Aula Abierta, 37(1), 67-78.

Escamilla (2012). Conocimiento del medio 4. Pixépolis. Madrid: Edelvives.

INE (2017). Fenómenos demográficos. Instituto Nacional de Estadística. Recuperado el 
23 de junio de 2017 desde http://www.ine.es/dyngs/INEbase/es/categoria.htm?c= Estadistica_P\&cid=1254735573002

Jennings, T. \& Macgillivray, I. K. (2011). A content analysis of lesbian, gay, bisexual, and transgender topics in multicultural education textbooks. Teaching Education, 22(1), 39-62. doi: $10.1177 / 0022487107313160$

Jessop, T. \& Williams, A. (2009). Equivocal tales about identity, racism and the curriculum. Teaching in Higher Education, 14(1), 95-106. doi: 10.1080/13562510802602681

Johnson, B. \& Christensen, L. (2004). Educational Research. Quantitative, qualitative, and mixed approaches. United States of America: Pearson Education.

López, F. (2006). Homosexualidad y familia: Lo que los padres, madres, homosexuales y profesionales deben saber y hacer. Barcelona: Graó.

Mancheño, R. (2012). Conocimiento del medio 2. Pixépolis. Madrid: Edelvives.

Morgado, B., Jiménez-Lagares, I. y González, M. M. (2009). Ideas del profesorado de primaria acerca de la diversidad familiar. Cultura y Educación, 21(4), 441-451. doi: 10.1174/113564009790002373

Ramírez, S., Moliner, V., y Vicente, L. (2007). Actitudes frente a las familias homoparentales en el contexto escolar. Castellón de la Plana: Servicio de Publicaciones de la Universidad Jaume I.

Ray, V. \& Gregory, R. (2001). School experiences of the children of lesbian and gay parents. Family Matters, (59), 28-34.

Rodrigo, M. J. y Palacios, J. (1998). La familia como contexto de desarrollo humano. En M. J. Rodrigo y J. Palacios (Eds.), Familia y Desarrollo Humano (pp. 24-44). Madrid: Alianza Editorial.

Rodríguez, G., Gil, J. y García, E. (1996). Metodología de la investigación cualitativa. Granada: Ediciones Aljibe.

Rowell, E. H. (2007). Missing!: Picture books reflecting gay and lesbian families. Young Children, 62(3), 24-26.

Ros, P. (2012). La inclusión de la diversidad afectivo-sexual y los nuevos modelos familiares en el ámbito educativo. Forum de Recerca, (17), 963-972. doi: 10.6035/ForumRecerca.2012.17.62

Segura, G. (2012). Conocimiento del medio 1. Pixépolis. Madrid: Edelvives.

Simons, H. (2011). El estudio de casos: teoría y práctica. Madrid: Morata.

Stake, R. E. (1998). Investigación con estudios de casos. Madrid: Morata

Torres, J. (1991). El currículum oculto. Madrid: Morata.

. (2008). Diversidad cultural y contenidos escolares. Revista de Educación, 345, 83-110.

. (2010). La educación de la ciudadanía en una sociedad globalizada. En F. Villalba y J.

Villatoro (Coords.), Aportaciones a la Educación Intercultural (pp. 17-30). Málaga: Letra25. . (2011). La justicia curricular. El Caballo de Troya de la cultura escolar. Madrid: Morata.

. (2015). Las autoridades quieren "tontos racionales". Entrevista a Jurjo Torres Santomé. Revista trabajadores/as de la enseñanza, 350, 22-25.

Travé, G., Pozuelos, F. J. y Cañal, P. (2013). Análisis de materiales curriculares y práctica docente. Cuadernos de pedagogía, 432, 51-53.

Trébol, G. (2012). Conocimiento del medio 3. Pixépolis. Madrid: Edelvives. 
